БРОДОВСКАЯ Елена Викторовна - доктор политических наук, профессор департамента политологии факультета социальных наук и массовых коммуникаций, директор центра политических исследований Финансового университета при Правительстве РФ (125993, Россия, г. Москва, ГСП-3, Ленинградский np-кm, 49; brodovskaya@inbox.ru)

лУКУШИН Владимир Андреевич - лаборант-исследователь иентра политических исследований, студент факультета социальных наук и массовых коммуникаций Финансового университета при Правительстве РФ (125993, Россия, г. Москва, ГСП-3, Ленинградский np-кm, 49; lukushin@ aol.com)

\title{
РОССИЙСКИЕ УНИВЕРСИТЕТЫ В СОЦИАЛЬНЫХ МЕДИА: ТРИ «ЦИФРОВЫЕ ЛИГИ»
}

\begin{abstract}
Аннотация. В статье представлены результаты анализа информационных потоков российских университетов социально-гуманитарного профиля в социальных медиа. Исследование шести кейсов на основе социально-медийной аналитики позволил выделить три «цифровых лиги» в Рунете: «лига» с доминированием традиционных каналов и форматов цифровых коммуникаций; «лига» с доминированием внешней информационной повестки; «лига» с максимальной диверсификацией каналов, форматов и аудиторий. Именно вузы условно третьей «цифровой лиги» обладают наиболее стабильными позициями на внутреннем рынке и во внешних рейтингах. Новизна исследования заключается в усовершенствовании методики оценки коммуникационного менеджмента университетов: она реализована на основе автоматизированного мониторинга цифровых следов.
\end{abstract}

Ключевые слова: цифровая инфраструктура, информационные потоки, цифровизация университета, социально-медийная аналитика, киберметрический анализ, когнитивное картирование, цифровые сообщества

Статья подготовлена по результатам исследований,
выполненныхзасчет бюджетныхсредств погосударственному
заданию Финансовому университету.

Постановка проблемы. У исследования цифровых коммуникаций российских университетов есть несколько актуальных социально-политических оснований. Во-первых, пандемия COVID-19 потребовала форсированного совершенствования цифровых инфраструктур и цифровых коммуникаций высших учебных заведений. Во-вторых, исследования свидетельствуют, что представленность информационных потоков вузов в социальных медиа отражает запрос потребителей [Бродовская и др. 2020]. В-третьих, система образования традиционно является одним из ключевых элементов «мягкой силы», и чем эффективнее вузы проявляют себя в цифровой среде, тем выше их потенциал влияния. И наконец, цифровая эпоха с гибридизацией медиасферы требует масштабирования репрезентации университетов в пространстве социальных медиа [Бродовская и др. 2019а]. Формирование новой методики оценки цифрового менеджмента университетов посредством автоматизированных сервисов является актуальным направлением исследовательской работы, отвечающим ключевым целям современной образовательной политики [Бродовская и др. 2019б; Бродовская и др. 2019в].

Методология и методика исследования. Методология исследования базируется на принципах социально-медийной предиктивной аналитики - современного исследовательского направления, предполагающего осуществление 
интеллектуального поиска маркеров цифровой активности и последующую автоматизированную обработку массива данных посредством специализированного программного обеспечения [Бродовская и др. 2017].

Исследование построено на сочетании методов, относящихся к количественной (киберметрия стихийных и целенаправленных информационных потоков в социальных медиа) и качественной (когнитивное картирование социальномедийных документов) стратегиях прикладного анализа. Выборку составили информационные потоки 6 ведущих российских университетов, занимающихся профессиональной подготовкой кадров финансово-экономического и социально-гуманитарного профиля, а также соответствующими направлениями научно-исследовательской деятельности (НИУ ВШЭ, Финансовый университет при Правительстве РФ, МГИМО, РУДН, РЭУ им. Г.В. Плеханова, РАНХиГС). Когнитивное картирование контента цифровых сообществ указанных университетов использовано для формирования словарей поисковых запросов, включающих формальные и неформальные наименования организаций, а также маркеры ключевых медиаперсон. База когнитивного картирования включила более 1000 цифровых публикаций. Киберметрический анализ осуществлен посредством использования инструмента автоматизированной обработки социальных медиа IQBuzz. Совокупный датасет составил 400 тыс. сообщений в 30 наиболее популярных цифровых площадках. Глубина анализа 01.03.2020-20.09.2021.

Результаты исследования. Анализ динамических характеристик информационных потоков университетов предполагает распределение выгруженного объема сообщений с соответствующими упоминаниями во времени. В течение 2020-2021 гг. ведущие отечественные вузы широкого социально-гуманитарного профиля демонстрируют высокий уровень конкуренции в цифровом пространстве (см. рис. 1). Старт ускоренной цифровизации и переход крупных университетов на дистанционный формат работы в условиях ухудшения эпидемиологической обстановки резко увеличили объемы информационного потока всех представленных университетов. На этом фоне достаточно активной в цифровом пространстве стала приемная кампания 2020 г. Большое значение имело введение возможности дистанционной подачи документов, что активизировало взаимодействие вузов с таргетными группами в онлайн-формате. К началу текущего года динамика информационных университетов снизилась до умеренных значений предыдущего периода.

Пиковые показатели информационной активности университетов в цифровой среде обусловлены различными типами событий. Для ряда университетов характерно информационное сопровождение собственных мероприятий (крупные научные конференции, форумы, образовательные проекты). Для РУДН, РЭУ и МГИМО особенно свойственно доминирование внутренних событий, формирующих информационный поток (около $70 \%$ сообщений внутри). Информационные потоки Финансового университета, НИУ ВШЭ и РАНХиГС диверсифицированы и ориентированы на публичные выступления представителей вузов в СМИ в качестве экспертов и комментаторов по актуальной социально-политической повестке (в среднем до $30 \%$ потока), обсуждение деятельности университета (20\%), презентацию результатов научноисследовательской деятельности (15\%).

Распределение общего числа сообщений позволило определить лидеров по организации системы цифровых коммуникаций. Абсолютным лидером по присутствию в социальных медиа является НИУ ВШЭ $(48,5 \%$ общего потока исследуемых вузов), в группу вузов со средними значениями входят Финуниверситет $(14,7 \%)$, РАНХиГС $(11,6 \%)$, МГИМО (11,6\%) и РУДН $(10,3 \%)$. Достаточно 
скромным на этом фоне является объем социально-медийного присутствия РЭУ (3,3\%). Важно отметить, что лишь один университет из выборки (НИУ ВШЭ) демонстрирует стремление к выполнению ключевого правила управления информационными потоками в цифровой среде - их равномерности.

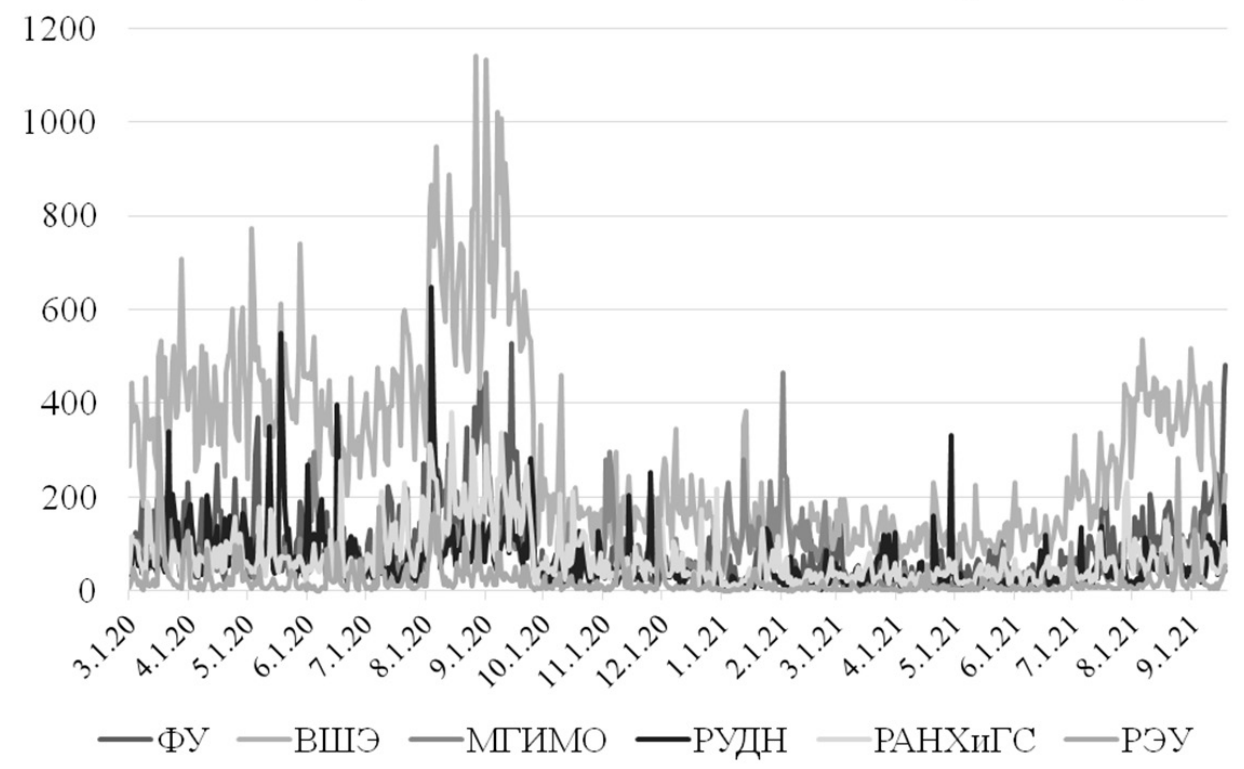

Рисунок 1. Динамика информационного потока российских университетов социально-гуманитарного профиля (2020-2021 гг.)

На основе анализа возрастных характеристик пользователей, вовлеченных в информационные потоки университетов, выделены две доминирующие возрастные группы: 26-35 и 36-45 лет, представленность которых является маркером развития цифрового менеджмента университета (см. табл. 1). Вузы с преобладанием в возрастной структуре группы 36-45 лет, а также значительным присутствием более старших групп (Финуниверситет, МГИМО, РАНХиГС, РЭУ) характеризуются развитием внешних стихийных потоков, не связанных напрямую с деятельностью университета. Напротив, вузы с доминированием молодежи в структуре цифровых пользователей нацелены на построение управляемой системы цифровых коммуникаций, обращенных преимущественно к университетскому сообществу и абитуриентам.

Значительным препятствием для отечественных университетов на пути к созданию функциональной цифровой инфраструктуры является сосредоточенность на одной платформе. Обработка массива сообщений с упоминанием университетов продемонстрировала, что от $82 \%$ до $93 \%$ их информационного потока приходится на единственную цифровую площадку - социальную сеть ВКонтакте (см. табл. 2). Несмотря на высокую популярность сервиса и массовость использования среди целевой аудитории вузов, данный факт не позволяет университетам масштабировать аудиторию и выходить на взаимодействие с дополнительными сегментами посредством новых форматов. В то же время на официальных сайтах университетов есть информация о представительствах в среднем на 6-7 цифровых площадках. В 2021 г. ряд университетов (НИУ ВШЭ, Финуниверситет) активно используют TikTok в качестве инструмента продвижения собственного бренда, а также Telegram для информирования 
Таблица 1

Возраст пользователей, вовлеченных в информационные потоки университетов социально-гуманитарного профиля

\begin{tabular}{|l|c|c|c|c|c|c|}
\hline \multicolumn{1}{|c|}{ Возраст/вуз } & $\mathbf{Ф У}$ & ВШЭ & МГИМО & РУДН & РАНХиГС & РЭУ \\
\hline Младше 16 & 1,1 & 2,2 & 0,7 & 0,6 & 1,0 & 0,8 \\
\hline $16-25$ & 14,3 & 18,2 & 16,1 & 24,8 & 20,2 & 15,8 \\
\hline $26-35$ & 23,7 & $\mathbf{3 1 , 3}$ & 25,1 & $\mathbf{2 9 , 8}$ & 24,1 & 22,2 \\
\hline $36-45$ & $\mathbf{2 7 , 9}$ & 26,2 & $\mathbf{2 7 , 1}$ & 23,5 & $\mathbf{2 9 , 3}$ & 25,4 \\
\hline $46-55$ & 17 & 14,3 & 17,3 & 12,2 & 14,7 & 22,6 \\
\hline $56-65$ & 16 & 7,8 & 13,7 & 9,1 & 10,7 & 13,2 \\
\hline
\end{tabular}

студентов и преподавателей и для формирования студенческих комьюнити. Продолжается активное внедрение социальных медиа в образовательный процесс. Отметим, что данный процесс должен стать трендом в развитии системы цифровых коммуникаций университетов.

Таблица 2

Локализация информационного потока университетов социально-гуманитарного профиля по сегментам Интернета

\begin{tabular}{|l|c|c|c|c|c|c|}
\hline \multicolumn{1}{|c|}{ Платформа/вуз } & ФУ & ВШЭ & МГИМО & РУДН & РАНХиГС & РЭУ \\
\hline ВКонтакте & 86 & 82 & 90 & 87 & 93 & 92 \\
\hline Одноклассники & 4 & 4 & 3 & 5 & 2 & 2 \\
\hline Facebook & 4 & 6 & 2 & 2 & 1 & 2 \\
\hline Instagram & 2 & 3 & 1 & 3 & 1 & 1 \\
\hline Twitter & 1 & 3 & 1 & 1 & 1 & 1 \\
\hline Другие & 3 & 2 & 3 & 2 & 2 & 2 \\
\hline
\end{tabular}

В ходе исследования зафиксирована взаимосвязь между объемом информационного потока, структурой вовлеченных пользователей и особенностями размещаемого контента. Содержание информационного потока каждого университета оценено через выгрузку наиболее встречаемых слов. Так, группа университетов показывает схожие смысловые ряды, связанные с обсуждением проблем внутренней и внешней политики, особенностями государственного управления, прогнозирования и оценки финансово-экономической ситуации (Финуниверситет - «экспертиза», «меры», «аналитика»; РАНХиГС «программа», «нацпроекты», «развитие»; МГИМО - «президент», «история», «компания»; РЭУ - «государственный», «работа», «вуз»). В информационном потоке РУДН наиболее употребляемыми являются лексические конструкции, отражающие внутреннюю деятельность университета («студенты», «конференция», «комиссия»). НИУ ВШЭ - единственный университет в выборке, где частотность внешних и внутренних конструкций является сопоставимой («городской», «экономика», «управление» и «студенческий», «лекция», «майнор»).

Результаты когнитивного картирования, определяющие содержательные 
характеристики потока, подтверждают, что наибольшую эффективность в контексте выстраивания устойчивых коммуникаций с таргетными группами современного университета (абитуриенты, студенты, преподаватели и сотрудники, научно-образовательное сообщество, широкая аудитория) имеет неформальный и разнообразный контент, способный как вовлечь новые сегменты аудитории, так и удержать постоянные.

Заключение. Анализ открытых цифровых следов ведущих университетов социально-гуманитарного профиля позволил выделить несколько групп, исходя из особенностей организации цифровых коммуникаций. Университеты первой группы отличаются низким объемом социально-медийного потока, отсутствием выраженного доминирования определенной возрастной группы в структуре пользователей, а также системной работы с цифровыми каналами коммуникации, ориентированием на единую цифровую площадку и внутреннюю аудиторию, формальным стилем цифрового менеджмента, слабой адаптивностью к новым форматам. Для вузов второй группы характерно наращивание информационного потока за счет внешних социально-политических событий, выступающих основой активности медиапредставителей университетов. Ключевыми площадками для них являются цифровые СМИ и форумы, что влияет на возраст аудитории. Ситуация с внутренними университетскими потоками приближена к вузам первой группы. Наконец, университеты третьей группы обладают наиболее эффективным набором характеристик системы цифровых коммуникаций: это высокий объем и равномерность информационного потока, разнообразие форматов, неформальность контента, стремление к диверсификации цифровых площадок, совмещение внутренних и внешних пользователей, избирательность в подборе контента для каждого аудитории.

Перспективным направлением исследования является оценка структурных характеристик крупнейших университетских сообществ в социальных сетях посредством методики социального графа. Данный метод позволит значительно расширить представленную типологизацию за счет анализа пользовательских связей внутри цифровых сообществ, получения данных о вовлеченности лидеров мнений в информационные потоки университетов.

\section{Список литературы}

Бродовская Е.В., Домбровская А.Ю., Карзубов Д.Н., Синяков А.В. 2017. Развитие методологии и методики интеллектуального поиска цифровых маркеров политических процессов в социальных медиа. - Мониторинг общественного мнения: экономические и социальные перемены. № 5. С. 79-141.

Бродовская Е.В., Домбровская А.Ю., Петрова Т.Э., Пырма Р.В., Азаров А.А. 2019а. Цифровая среда ведущих университетов мира и РФ: результаты сравнительного анализа данных сайтов - Высшее образование в России. Т. 28. № 12. C. 9-22.

Бродовская Е.В., Домбровская А.Ю., Пырма Р.В., Синяков А.В., Азаров А.А. 2019б. Построение модели влияния современных цифровых коммуникаций на профессиональные компетенции российской молодежи. - Информационное общество. № 4-5. С. 33-43.

Бродовская Е.В., Домбровская А.Ю., Пырма Р.В., Азаров А.А. 2019в. Стратегии цифрового поведения российской молодежи в контексте формирования гражданских и профессиональных компетенций. - Свободная мысль. № 4(1676). С. 109-118.

Бродовская Е.В., Домбровская А.Ю., Пырма Р.В., Азаров А.А. 2020. Критерии для рейтингования уровня и качества цифровизации процесса образования 
в вузах РФ. - Вестник Волгоградского государственного университета. Сер. 4: История. Регионоведение. Международные отношения. Т. 25. № 2. С. 268-283.

BRODOVSKAYA Elena Viktorovna, Dr.Sci. (Pol.Sci.), Professor of the Department of Political Science, Faculty of Social Sciences and Mass Communications, Director of the Center for Political Studies, Financial University under the Government of the Russian Federation (49 Leningradsky Ave, GSP-3, Moscow, Russia, 1259930; brodovskaya@inbox.ru) LUKUSHIN Vladimir Andreevich, Research Assistant at the Center for Political Studies, student of the Faculty of Social Sciences and Mass Communications, Financial University under the Government of the Russian Federation (49 Leningradsky Ave, GSP-3, Moscow, Russia, 1259930; lukushin@aol.com)

\title{
RUSSIAN UNIVERSITIES IN SOCIAL MEDIA: THREE «DIGITAL LEAGUES»
}

\begin{abstract}
The article presents the results of the analysis of information flows of Russian universities in the social and humanitarian profile in social media. The study of six cases based on social media analytics made it possible to single out three «digital leagues» in Russian Internet: a «league» dominated by traditional channels and formats of digital communications; a «league» dominated by an external information agenda; a «league» with maximum diversification of channels, formats and audiences. It is the universities of the conditionally third "digital league» that have the most stable positions in the domestic market and in external ratings. The novelty of the research lies in improving the methodology for assessing the communication management of universities: it is implemented on the base of automated monitoring of digital traces.
\end{abstract}

Keywords: digital infrastructure, information flows, university digitalization, social media analytics, cybermetric analysis, cognitive mapping, digital communities

КУРЮКИН Андрей Николаевич - кандидат политических наук, старший научный сотрудник центра комплексных социальных исследований Института социологии Федерального научно-исследовательского социологического центра РАН (117218, Россия, г. Москва, ул. Кржижсановского, 24/35, кopn.5; kuriukin@mail.ru)

\section{АКТУАЛЬНЫЕ ТЕНДЕНЦИИ ПОЛИТИЧЕСКОГО РАЗВИТИЯ ПО ХОДУ ПАНДЕМИИ COVID-19 И ПОСЛЕДУЮЩЕЙ «НОВОЙ НОРМАЛЬНОСТИ»}

\begin{abstract}
Аннотация. Центральным вопросом постковидной политики выступит вопрос, вызовет ли пандемия к жизни антидемократический откат и эволюционирующую авторитаризацию власти или, напротив, станет толчком для позитивного развития демократии, повышения роли гражданского общества и политической партиципации граждан. Объективно мировая политика будет испытывать неслыханные трансформационные нагрузки под воздействием длящегося пандемического кризиса, но в то же время окажется перед выбором - сохранять кризисную стагнацию, надеясь его «просто пережить», или воспринимать кризис как источник новых возможностей для развития и прогресса.
\end{abstract}

Ключевые слова: политика, глобализация, партии, политический процесс, демократия, выборы, коронавирус

Ллобальное воздействие пандемии коронавируса ставит два взаимосвязанных вопроса: выступит ли пандемия поворотным историческим момен- 